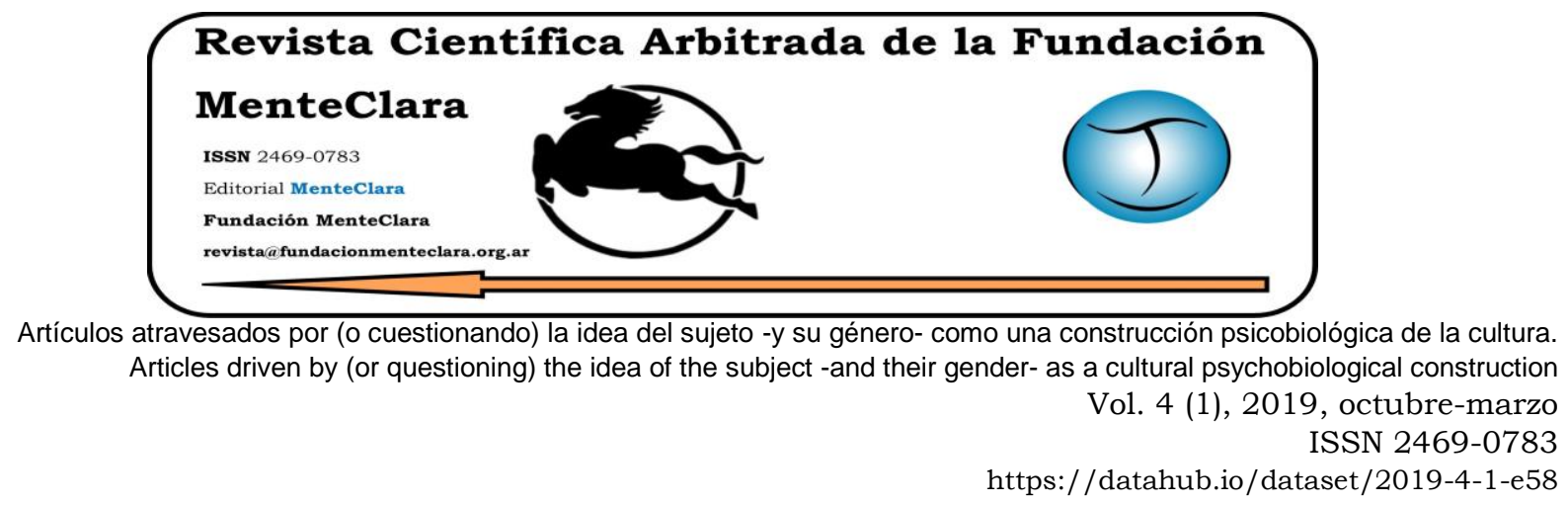

\title{
ANÁLISIS DEL CIBERPERIODISMO EN MÉXICO, CON ÉNFASIS EN EL ESTADO DE SINALOA
}

\author{
ANALYSIS OF CYBERJOURNALISM IN MEXICO, WITH EMPHASIS ON THE STATE \\ OF SINALOA
}

Mario Guadalupe López Ayala1; Israel Osuna Flores²

Cómo citar este artículo / Citation: Lopez Ayala M. G., Osuna Flores I. (2019). "Análisis del ciberperiodismo en México, con énfasis en el estado de Sinaloa". Revista Cientifica Arbitrada de la Fundación MenteClara, 4(1) octubre-marzo 2019, 7-30.

DOI: https://doi.org/10.32351/rca.v4.1.58

Copyright: (C) 2019 RCAFMC. Este artículo de acceso abierto es distribuido bajo los términos de la licencia Creative Commons Attribution 4.0 International License (CC BY 4.0). Recibido: 29/11/2018. Aceptado: 09/12/2018 Publicación online: 30/04/2019

Conflicto de intereses: Ninguno que declarar.

\section{Resumen}

Se hace una revisión y análisis del ciberperiodismo en México con énfasis en el estado Sinaloa, tomando en cuenta los principales trabajos de reconocidos investigadores en el ciberperiodismo en Iberoamérica y México y se realizó una investigación sobre el estado actual del periodismo digital en el estado de Sinaloa. En él se contempla los principales antecedentes del periodismo digital a nivel nacional y estado; así como, la discusión sobre la problemática actual y perspectivas a futuro. En México, se han dado casos aislados de trabajos de investigación sobre el desarrollo y actuación de los periódicos digitales mexicanos, registrándose apenas unos pocos textos acerca de esta actividad informativa; todos ellos desarticulados, por lo que no se puede considerar que exista un claro intento a nivel nacional para develar las particularidades del ciberperiodismo mexicano; la academia mexicana tiene un déficit

\footnotetext{
${ }^{1}$ Ingeneiro industrial, Periodista, Catedrático en Universidad Autónoma de Occidente (UAO) y Universidad Autónoma de Sinaloa (UAS), México. e-mail: phoenixmedios@yahoo.com

2 Biologo Pesquero, Especialista en Medio Ambiente, Columnista, Asesor de la Empresa Acuícola Gilberto SC de RL de CV, México. e-mail: osuna2017@gmail.com
} 
en este punto. Son pocos los trabajos que describen el desarrollo y análisis del periodismo digital en México y escasos antecedentes para el estado de Sinaloa; y que en ambos casos, se tiene una discontinua información, observándose que el ciberperiodismo en México y en Sinaloa está dentro de las primeras fase de su desarrollo. Una tendencia interesante detectada en este análisis fue que varios de los cibermedios mejor valorados pertenecen a la zona noroeste de México, conformada por los estados de Sinaloa, Sonora y Baja California Norte, lo que indica una tendencia de competencia positiva en esa región y un claro avance en el estado de Sinaloa, México.

\section{Abstract}

A review and analysis of the cyberjournalism in Mexico is made, with emphasis on the Sinaloa state, taking into account the main works of renowned researchers in the cyberjournalism in Latin America and Mexico and an investigation was made about the current state of digital journalism in the state of Sinaloa. It covers the main antecedents of digital journalism at national and state level; as well as, the discussion on the current problems and future perspectives. In Mexico, there have been isolated cases of research on the development and performance of Mexican digital newspapers, with only a few texts about this informative activity; all of them disjointed, so it can not be considered that there is a clear attempt at the national level to unveil the particularities of Mexican cyberjournalism; The Mexican academy has a deficit at this point. There are few works that describe the development and analysis of digital journalism in Mexico and few antecedents for the state of Sinaloa; and that in both cases, there is a discontinuous information, observing that the cyberjournalism in Mexico and Sinaloa is within the early stages of its development. An interesting trend detected in this analysis was that several of the most valued cybermedia belong to the northwestern area of Mexico, formed by the states of Sinaloa, Sonora and Baja California Norte, which indicates a positive competition trend in that region and a clear advance in the state of Sinaloa, Mexico.

Palabras Claves: Ciberperiodismo; Periodismo digital; estado actual de los ciberperiódicos en Sinaloa; México

Keywords: Cyberjournalism; digital journalism; current status of cyber newspapers in Sinaloa; Mexico 


\section{Introducción}

La práctica del periodismo en Internet, denominada ya generalizadamente como ciberperiodismo, se ha convertido en los últimos años en el referente necesario para entender la evolución que ha tenido el periodismo como tal, tanto en su aspecto profesional, como en el del papel que social y políticamente ha desempeñado la prensa desde hace décadas (Barios, 2013).

El primer diario que diseñó una edición digital (con el contenido íntegro de la versión impresa) fue el estadounidense San José Mercury News (1994). Durante su primer año, el costo por consulta ascendía a 9.95 dólares por cinco horas y 3.50 dólares por cada hora adicional. En 1998 se redujo la tarifa a 5 dólares mensuales y poco después se convirtió en un servicio gratuito (Navarro, 2011).

El concepto de "ciberperiodismo" fue postulado por teóricos españoles entre los que destacan Javier Díaz Noci y Ramón Salaverría; este último apoya la nueva denominación porque recoge el espíritu del nuevo medio, y la define como "la especialidad del periodismo que emplea el ciberespacio para investigar, producir y, sobre todo, difundir contenidos periodísticos" (Barrios, 2013).

Gil (1999), menciona que el verdadero periodismo digital rompe con la comunicación lineal y unidireccional de un emisor a un receptor. Es decir, se redefine la relación emisor/receptor, y da paso a una retroalimentación real y permanente.

Morales (2005) divide el desarrollo de este tipo de periodismo en tres generaciones:

1. Periodismo 1.0 o de primera generación. Cuando los medios impresos, al acceder al soporte digital, vuelcan de manera literal lo publicado en el papel. 
2. Periodismo 2.0 o de segunda generación. Los diarios digitales desarrollan nuevos tipos de narrativa, aún dependientes del soporte papel y del discurso digital analógico

3. Periodismo 3.0 o de tercera generación. Aquí, los cibermedios alcanzan autonomia respecto a las versiones impresas. Surgen iniciativas empresariales y editoriales para crear contenidos y narrativas acordes con las características de internet.

Una gran parte de los diarios digitales en Latinoamérica aún se ubican en la fase 1.0 (Rivera, 2009), ya que poseen características propias de medios tradicionales, sin pretender un aprovechamiento de los recursos que caracterizan al cibermedio.

La Asociación Mundial de Periódicos (AWN, en sus siglas en inglés) reportó a través de su informe Tendencias mundiales de prensa, publicado en 2011, que la distribución de prensa diaria a nivel mundial llegó a 540 millones de copias, pero ha disminuido en un 3.9 por ciento en los últimos cuatro años. Al igual que Asia, Latinoamérica mostró un avance positivo, sin embargo, Europa y América del Norte mostraron un retroceso luego de registrar caídas en sus circulaciones de hasta un 30 por ciento (Espinosa, 2013).

Ross Dawson, a través de la empresa australiana Future Exploration Network, llevó a cabo en 2010 la investigación Newspaper extinction timeline, para estimar el año en que los diarios impresos en el mundo serán rebasados por los cibermedios. Los factores que desatarán este evento, prevé el investigador, son el desarrollo de las industrias cibermediáticas, el incremento en el número de internautas, cambios en la conducta de los lectores y la disminución en la brecha digital de cada país (Espinosa, 2013). 
Los medios impresos de Estados Unidos serán los primeros en el mundo en verse afectados. Dentro de Iberoamérica, España será el primer país en sufrir los efectos de esta crisis, en 2024. Le siguen Brasil, en 2027, y México, en 2033. Los medios impresos que se verán más afectados serán los ubicados en sus áreas metropolitanas. El efecto dominó continuará en Uruguay y Chile para el 2035. Cuatro años después, llegará a Argentina. El resto de los países en Latinoamérica se verán afectados después del 2040 (Espinosa, 2013).

La creación de las versiones digitales de los periódicos impresos mexicanos tuvo un desarrollo acelerado al final del siglo XX y principios del XXI, de manera tal que en la actualidad todos los diarios que se consideran con algún grado de relevancia tienen su sitio informativo en la red (Barrios, 2013).

El periodismo mexicano ha incursionado en Internet al igual que sus homólogos de otros países. La mayoría de los diarios impresos que circulan en México tienen ya su sitio en la web, a través del cual difunden las noticias que han aparecido en sus versiones en papel y, en algunos casos, incluyen historias preparadas exclusivamente para el entorno digital (Barrios, 2013).

Barrios (2013) menciona que el periodismo en México ha tenido un destacado papel en el funcionamiento cotidiano de las comunidades a las que sirve. En su versión impresa, tradicionalmente ha asumido una posición de influencia sustantiva en el acontecer politico y social en muchas regiones del país. Por ello, analizar la eficiencia con la que se desenvuelve en el nuevo entorno que constituye Internet, dilucidar en qué medida está aprovechando o no las ventajas intrínsecas que le aporta el entorno en línea, se revela como una necesidad para dimensionar los alcances que tendrá a mediano y largo plazo el periodismo mexicano instalado en Internet. 
En esta misma área de conocimiento, en México han aparecido algunos textos que abordan la cuestión desde la óptica local, destacando los generados por Trejo (1996), La Nueva Alfombra Mágica y por Islas et al, Internet: el medio inteligente (2000).

Hay una tendencia de los cibermedios mejor valorados en la zona noroeste de México, conformada por los estados de Sinaloa, Sonora y Baja California Norte, en la que se destacan los periódicos el Debate y el Noroeste en Sinaloa (Barrios, 2013).

A pesar de los anteriores avances en el periodismo cibernético en Sinaloa es necesario subsanar las graves carencias en el uso de las herramientas propias del entorno digital que señalan un problema serio: es indispensable determinar sus causas, que pueden provenir desde las estrecheces económicas hasta la falta de capacitación y conocimiento sobre las potencialidades de tales recursos, además de que las redacciones digitales mexicanas no cuentan con estructuras laborales y profesionales adecuadamente identificadas. Se advierten esfuerzos dispersos y sin objetivos adecuados, para lo cual el proposito de la presente propuesta se enfoca en analizar la situación actual del periodismo cibernético en Sinaloa.

\section{Metodologia.}

Para la realización de este trabajo fueron tomados en cuenta los trabajos de diferentes autores que han venido describiendo y analizando el ciberperiodismo en México, además se ha incluido una revisión del estado actual del ciberperiodismo en Sinaloa. 


\section{Antecedentes del surgimiento del ciberperiodismo}

A veintiún año distancia de la fecha a la que convencionalmente se ha considerado como el momento de nacimiento del ciberperiodismo, 1994, es posible afirmar que la literatura académica que analiza este fenómeno comunicativo se ha diversificado y ofrece la posibilidad de analizarlo desde distintos puntos de vista, no solo en función de la teoría y la práctica, sino también en cuanto a enfoques regionales, generándose ya tendencias en el estudio del ciberperiodismo que pueden ser identificadas en relación a la zona del mundo de la que provienen (Barrios, 2013).

En México han aparecido algunos textos que abordan la cuestión desde la óptica local, destacando los generados por Trejo (1996), La Nueva Alfombra Mágica y por Islas, Gutiérrez et al, Internet: el medio inteligente (2000), todos ellos establecen un punto de partida para comprender más ampliamente las modalidades de penetración de Internet en este país, según lo menciona (Barrios, 2013).

Los primeros libros que tenían como tema central al ejercicio del periodismo en Internet Armañanzas, Díaz y Meso (1996) abrieron el camino con la obra El periodismo electrónico, información y servicios multimedia en la era del ciberespacio. Apenas unos años después, Díaz y Meso (1999) presentaron conjuntamente el libro Periodismo en Internet, modelos de la prensa digital, con la que se han basado buena parte de los análisis posteriores.

En 2003 se publica el Manual de Redacción Ciberperiodística coordinado por Ramón Salaverría y Javier Díaz Noci, en las que se analizan las modalidades con las que se trabaja y produce el ciberperiodismo.

En Latinoamérica las contribuciones al estudio del ciberperiodismo no han sido tan numerosas, destacan algunas obras como la coordinada por 
Palacios y Díaz (2007) Ciberperiodismo, métodos de investigación. Una aproximación multidisciplinar en perspectiva comparada, en la que exponen las diferentes metodologias del ciberperiodismo. Entre otras obras importantes tenemos los trabajos de Franco (2008, 2009 y 2010) impulsados por el Centro Knight para el Periodismo en las Américas donde presentan la forma de operación de los cibermedios de esta región.

El ciberperiodismo en México nace en los primeros meses de 1995, con la apertura del sitio del periódico capitalino La Jornada (Trejo, 1996).

Los primeros dos años de su existencia se caracterizaron por un crecimiento lento de los números de medios periodísticos en línea y no es hasta finales de la década de los noventa, en el que se llegaron a registrar hasta 170 publicaciones diarias (Navarro, 2002).

En México la investigación sobre ciberperiodismo ha sido escasa. Navarro $(2002,2005,2012)$ de la Universidad de San Luis Potosí es la autora con mayor número de obras sobre el tema, donde aborda aspectos descriptivos, en 2005 Crovi, Toussaint y Tovar generaron el texto denominado Periodismo Digital en México. Octavio Islas coordinó en 2002 Explorando el ciberperiodismo latinoamericano, recopilando artículos de autores con perspectivas muy diversas.

De manera más reciente, López (2010) presenta su tesis doctoral sobre la ciberdocumentación en la prensa digital mexicana. Meneses en 2010, publicó el Periodismo convergente, tecnología, medios y periodistas en el siglo XXI; esporádicamente hay otros trabajos que presentan comunicaciones o artículos en revistas especializadas.

A finales del 2010, se encontraron un total de 449 sitios de internet dedicados a la información periodística en todo el país, de los cuales 337 tenían un referente impreso y 112 existian solo en línea (Barrios, 2013). 
Este aumento en las cifras no ha sido a la par en cuanto a la calidad de los medios en línea mexicanos (López, 2010); los de mejor calidad se concentran en las grandes ciudades del país y la mayoría de los sitios restantes presentan servicios bastante rudimentarios comprándolos con otros países.

Lo anterior tiene su explicación debido a las características socioeconómicas de México: el acceso a Internet aun no es generalizado; existen aún amplios sectores de la población y regiones en las que la penetración de internet es bastante baja, por lo que la amplia difusión territorial de los cibermedios es alentadora en ese contexto (Barrios, 2013).

Los alcances profesionales de la la prensa nacional escrita en el Distrito Federal han sido mucho mayores respecto a los diarios del interior del país. Siendo similar en el caso de la operación en Internet.

Recientemente Crovi (2016) nos presenta un interesante relato del ciberperiodismo en México (1995-2014) mencionando que pionera de todos los cambios que ha experimentado el periodismo, la prensa mexicana también lo fue al incursionar en Internet. Pueden distinguirse tres etapas. La primera se dio a mediados de los años ochenta del siglo XX y fue producto de la incorporación de computadoras a las redacciones. Para finales de esa década, casi la mitad de los diarios nacionales se habian automatizado, en tanto que el resto ya disponía de computadoras (Menéndez y Toussaint, 1989). La segunda etapa consistió en mostrar en línea, de manera sistemática y con acceso libre, versiones concebidas como espejo de sus ediciones impresas. A este período corresponden los primeros acercamientos, alrededor de 1995, de La Jornada de la ciudad de México y El Norte de Monterrey, que comienzan a colgar sus contenidos impresos en un sitio web abierto especialmente para ello. Esas réplicas del formato papel aún hoy persisten en periódicos 
locales o de escaso tiraje. Finalmente, una tercera etapa, en la que nos encontramos, consistió en la incorporación franca, aunque desigual, de la prensa on line a las ventajas de la convergencia digital, aprovechando recursos interactivos y buscando una relación dialógica con el lector. Casi todos los diarios de circulación nacional y/o regional de importancia adoptan desde entonces la tendencia de estar presentes en la red. Como decíamos, la segunda etapa comienza a mediados de los años noventa, con la aparición de las primeras publicaciones digitales (Corvi, 2016).

En provincia algunos de los casos destacados son las páginas electrónicas de diarios como El Siglo de Torreón, El Imparcial de Sonora, El Debate y Noroeste de Sinaloa, además de Frontera y Crónica de Baja California Norte. Todos ellos sumaron puntuaciones que se asemejaron a diarios en línea con una tradición importante en el periodismo mexicano, tales como Excélsior o La Jornada (Barrios, 2013).

Una tendencia interesante detectada en este análisis fue que varios de los cibermedios mejor valorados pertenecen a la zona noroeste de México, conformada por los estados de Sinaloa, Sonora y Baja California Norte, lo que indica una tendencia de competencia positiva en esa región (Barrios, 2013). 


\section{Uso y apropiación de tecnología en relación al ciberperiodismo en México y Sinaloa}

Las cifras que aporta el Instituto Nacional de Estadística y Geografia (INEGI) de México reportadas por Corvi (2016) reportan que el acceso de los ciudadanos a las redes digitales experimenta un crecimiento situado en el 13,9\% entre 2006 y 2013, insuficiente para transformar el modelo social en una sociedad de la información.

El INEGI indica que en 2001 México contaba con 7,1 millones de usuarios, cifra que en 2005 fue de 16,4 millones. Cinco años más tarde, en 2010, 32,8 millones de ciudadanos disponían del servicio; el dato más reciente es el de 2013, que señala que 46 millones de mexicanos acceden a Internet, lo que representa un $43,5 \%$ frente al total de la población, cifrada en 120,8 millones de personas en 2012. De ellos, 74,3 \% tienen entre 6 y 35 años, y 64,3 \% marcan la búsqueda de información como actividad preponderante en Internet. Esta preferencia, sin embargo, comprende muchos tipos de información que van más allá de la estrictamente periodística. Datos del INEGI del mismo año 2013 indican que 44,7 millones de mexicanos usan computadoras, en tanto que el país registra 102,2 millones de líneas de móviles, que representan una penetración del 86,3 \%. Con relación al acceso a la banda ancha, en 2014 aún son numerosos los ciudadanos que no obtienen sus beneficios (Corvi, 2016). Datos más recientes muestran el número de hogares con internet e México (Tabla 1). 
Tabla 1. Número de hogares con internet en México

\begin{tabular}{|l|c|}
\hline Años & Millones de hogares \\
\hline 2001 & 1.5 \\
\hline 2002 & 1.8 \\
\hline 2004 & 2.3 \\
\hline 2005 & 2.3 \\
\hline 2006 & 2.7 \\
\hline 2007 & 3.2 \\
\hline 2008 & 3.8 \\
\hline 2009 & 5.1 \\
\hline 2010 & 6.3 \\
\hline 2011 & 7.0 \\
\hline 2012 & 7.9 \\
\hline 2013 & 9.6 \\
\hline 2014 & 10.8 \\
\hline 2015 & 12.8 \\
\hline
\end{tabular}

Fuente: Tomado de Corvi, 2016.

En estas cifras percibimos un crecimiento en el acceso a los recursos básicos de la digitalización, pero también indican un gran volumen de ciudadanos excluidos (6 de cada 10 mexicanos, aproximadamente). Además, existen diferencias regionales: el porcentaje de hogares con conexión a Internet en zonas urbanas es del 30\%, cifra que supera por mucho el 4\% para hogares en zonas rurales (Encuesta Nacional de Ingresos y Gastos de los Hogares, 2012). La brecha digital originada en razones socioeconómicas refiere que, si bien tres cuartas partes de los hogares de mayor poder adquisitivo tienen acceso a la red, apenas 2 de 
cada 100 hogares entre los más pobres del país cuentan con esta posibilidad (Piedras y Camargo, 2014).

Los datos aportados muestran que aún hay retos importantes por superar que impactan en la evolución del ciberperiodismo y que exigen tomar medidas apremiantes. Por un lado, aprobar las reglamentaciones secundarias de la Ley Federal de Telecomunicaciones, que busca acotar el poder de los actores dominantes del sector; por otro, aplicar certeramente políticas de inclusión digital que aumenten la actual penetración de banda ancha, hoy del 24\%, hasta llegar en cinco años a un $70 \%$ (Piedras y Camargo, 2014).

Más infraestructura y un marco legal más equitativo pueden establecer diferencias para lograr un acceso menos excluyente a la información digital y a las acciones sociales en las que están vinculados los procesos de digitalización. Reiteramos también la necesidad de un profundo cambio en el sector educativo que permita acortar la brecha cognitiva y desarrolle en los ciudadanos habilidades digitales que les lleven a aprovechar, entre otras muchas cosas, las posibilidades que ofrece el ciberperiodismo como elemento coadyuvante en el proceso de construcción de su realidad simbólica. En este mismo sentido, es imprescindible iniciar estudios que, más allá de las cifras duras, aporten datos sobre los procesos de uso y apropiación de las tecnologías digitales, que puedan establecer características situadas en la realidad nacional y sus diferentes matices (Corvi, 2016).

INEGI (2015) reveló que 55.7 millones de personas son usuarios de una computadora y 62.4 millones utilizan Internet en México. Al considerar el uso de las TIC por género, los resultados mostraron una participación equitativa entre mujeres y hombres: 49.2 y 50.8 por ciento en el uso de computadora, y de 49.4 y 50.6 por ciento en el de Internet, respectivamente. 
Sinaloa, ocupa el lugar número 20 en porcentaje de hogares con internet en México, mientras que en cuanto a los porcentajes de internet por usuario lo colocan en el número $15 \mathrm{y}$ en cuanto usuarios con computadora por estado se coloca en el número 17 y en relación a usuarios de telefonía celular se posiciona en un buen cuarto lugar (INEGI, 2015).

\section{Situación actual del ciberperiodismo en México y Sinaloa}

Hoy en día donde el desarrollo de las TICS ha tenido un avance significativo, sobre todo a finales del siglo pasado y en el presente, el periodismo digital o ciberoeriodimso ha tenido un aumento gradual, por la necesidad de estar a la par y aprovechar este medio de comunicación masiva de internet. Sin embargo la ventaja comparativa en las características de este periodismo cibernético en contraste con el periodismo tradicional aún dista de ser equitativamente comparado al de la prensa impresa.

Por otro lado tenemos que en la actualidad se está teniendo un decremento en la circulación del periodismo tradicional a nivel mundial y en México no es la excepción, y existen datos futurísticos de la posible desaparición de los medios impresos y su substitución por el cieberperiodismo tal y como se expone en el apartado de introducción de este trabajo.

En México son escaso los estudios que abordan la temática de investigación por un lado del ciberperiodismo y por otro de la situación actual del periodismo tradicional o impreso, a pesar de la vertiginoso avance de la prensa digital, lo que tendrá que poner mayor énfasis en solucionar este tipo de problemas diferenciales y hasta cierto punto 
paradójicas entre estos dos medios de comunicación digital e impreso del periodismo en México.

Se han dado casos aislados de trabajos de investigación sobre el desarrollo y actuación de los periódicos digitales mexicanos, registrándose apenas unos pocos textos acerca de esta actividad informativa; todos ellos desarticulados, por lo que no se puede considerar que exista un claro intento a nivel nacional para develar las particularidades del ciberperiodismo mexicano; la academia mexicana tiene un déficit en este punto (Barrios, 2013).

Según Barrios (2013), esta nueva forma de ejercer el periodismo carece de teoría y manuales actualizados con las últimas innovaciones tecnológicas y lingüísticas. Pese a ello, los lectores demandan un nuevo perfil de los periodistas, que se adapte mejor a las particularidades de su medio de trabajo, internet, y que les permita moverse con rapidez entre la información a cubrir. Los ciberperiodistas deben poseer la capacidad de decidir a contrarreloj, experiencia en trabajo en grupo, capacidad de interpretación y destreza para relacionar los hechos con eventos similares que involucren la misma lógica

Barrios (2013), da a conocer una tendencia en la que varios de los cibermedios mejor valorados pertenecen a la zona noroeste de México, conformada por los estados de Sinaloa, Sonora y Baja California Norte, lo que indica una tendencia de competencia positiva en esa región, en la que se destacan los periódicos el Debate y el Noroeste en Sinaloa.

En la tabla número 2, se puede observar la cantidad de periódicos digitales existentes en Sinaloa 


\section{Tabla 2. Relación de periódicos digitales en el estado de Sinaloa.}

\begin{tabular}{|c|c|}
\hline Periódico digital & Página web \\
\hline $\begin{array}{l}\text { Periodismo entre balas: Nace } \\
\text { un medio digital en Sinaloa } \\
\text { "La Pared" }\end{array}$ & $\begin{array}{l}\text { www.laparednoticias.com/periodismo-entre-balas- } \\
\text { nace-un-medio-digital-en-sinaloa/ }\end{array}$ \\
\hline $\begin{array}{l}\text { Al Instante Noticias. El primer } \\
\text { diario digital de Sinaloa }\end{array}$ & www.alinstantenoticias.com/ \\
\hline $\begin{array}{l}\text { Reporte } 18 \text { El periódico digital } \\
\text { de Sinaloa }\end{array}$ & www.reporte $18 . \mathrm{com} /$ \\
\hline $\begin{array}{l}\text { Punto Mx El periódico de } \\
\text { Vanguardia en Sinaloa. }\end{array}$ & www.punto.mx/ \\
\hline El Sol de Sinaloa & https://www.elsoldesinaloa.com.mx/ \\
\hline Rio 12 & $\underline{\text { https: //riodoce. } \mathrm{mx} /}$ \\
\hline Línea Directa Portal & https://www.lineadirectaportal.com/ \\
\hline $\begin{array}{l}\text { Periódico viva voz diario } \\
\text { digital }\end{array}$ & $\underline{\text { www.vivavoz.com.mx }}$ \\
\hline Sinaloa El debate & https://www.debate.com.mx/seccion/sinaloa/ \\
\hline Periódico Noroeste & www.noroeste.com.mx/ \\
\hline $\begin{array}{l}\text { Razones.com. Sinaloa en el } \\
\text { mudo. Periodismo alternativo }\end{array}$ & http://www.rrazones.com/ \\
\hline $\begin{array}{l}\text { Café negó portal el mejor } \\
\text { portal de noticias de Sinaloa }\end{array}$ & www.cafenegroportal.com/ \\
\hline $\begin{array}{l}\text { Proyecto } 3 \text { Voces que rompen } \\
\text { el silencio }\end{array}$ & www.proyecto3. $\mathrm{mx} /$ \\
\hline Por los pasillos & www.porlospasillos.com.mx/ \\
\hline $\begin{array}{l}\text { Columna periodistica sin } \\
\text { redundar Carlos Avendaño }\end{array}$ & www.carlosavendano.com.mx \\
\hline
\end{tabular}




\begin{tabular}{|c|c|}
\hline PHOENIXMEDIOS & http://www.phoenixmedios.com/ \\
\hline $\begin{array}{l}\text { Fuentes Fidedignas Diario } \\
\text { Digital }\end{array}$ & www.fuentesfidedignas.com.mx/ \\
\hline $\begin{array}{l}\text { Periódico Oficial del Estado de } \\
\text { Sinaloa - Gobierno del Estado } \\
\text { de Sinaloa }\end{array}$ & $\begin{array}{l}\text { https:// sinaloa.gob.mx/p/secretaria-general-de- } \\
\text { gobierno/periodico-oficial-del-estado-de-sinaloa }\end{array}$ \\
\hline $\begin{array}{l}\text { SinaloaNEWS - Soy del mero } \\
\text { Sinaloa donde se rompen las } \\
\text { olas }\end{array}$ & www.sinaloanews.mx/ \\
\hline El informativo del Malecón & https://www.facebook.com/elinformativodelmalecon \\
\hline El Chismorreo Noticioso & $\begin{array}{l}\text { https://www.facebook.com/search/posts } / ? \mathrm{q}=\mathrm{el} \% 20 \\
\text { chismorreo\%20noticioso }\end{array}$ \\
\hline Luz Noticias Sinaloa & https://www.luznoticias.mx/ \\
\hline Semanario de Sinaloa & www.grupouriberso.com/ \\
\hline $\begin{array}{l}\text { Las Noticias Culiacán TVP } \\
\text { TVPACIFICO.MX }\end{array}$ & $\begin{array}{l}\text { https://tvpacifico.mx/programas/las-noticias- } \\
\text { culiacan }\end{array}$ \\
\hline El Mitotero de Sinaloa & $\begin{array}{l}\underline{\text { https://www.facebook.com/messages/t/951880048 }} \\
\underline{190893}\end{array}$ \\
\hline $\begin{array}{l}\text { Sinaloa en Linea Información } \\
\text { en tiempo real SINALOA EN } \\
\text { LINEA }\end{array}$ & www.sinaloaenlinea.com/ \\
\hline Red noticias 23 & http://rednoticias23.com/ \\
\hline Sinaloa Semanario Mercurio & www.periodicomercurio.com \\
\hline $\begin{array}{l}\text { Así es la Política. La verdad a } \\
\text { su servicio. }\end{array}$ & http://asieslapolitica.com/pagina-ejemplo/ \\
\hline $\begin{array}{l}\text { Trópico de Cáncer Canal de } \\
\text { Telvsiòn }\end{array}$ & $\begin{array}{l}\underline{\text { https://www.facebook.com/tropicodecancermazatla }} \\
\text { n/?hc_ref=ARRgUbwOonJMAViw1sfgVhpvoV9GODRf68p } \\
\underline{\text { Ne_Jn }}\end{array}$ \\
\hline TV Azteca Sinaloa & https://www.facebook.com/aztecasin/ \\
\hline TVP Mazatlán & https://www.facebook.com/TVPMazatlan/ \\
\hline Canal 7 Mazatlán & $\begin{array}{l}\text { https://www.facebook.com/Canal-7- } \\
\text { Mazat1\%C3\%A1n-335880333282861/ }\end{array}$ \\
\hline
\end{tabular}




\begin{tabular}{|c|c|}
\hline $\begin{array}{l}\text { Sintesis de Prensa Dr. Héctor } \\
\text { Muñoz }\end{array}$ & $\begin{array}{l}\text { http://sintesisdeprensadrhectormunoz.com/newpre } \\
\text { view.php?id=1921\&tipo=1 }\end{array}$ \\
\hline Noticias en la Mira & $\begin{array}{l}\quad \text { https://www.facebook.com/jorgepasosenlamira/?hc } \\
\text { ref=ARTbMtjm74vjPRsTFOyNueSPt9BKHYMe94Q7AjVh } \\
\underline{\text { X9xG7xZlqyK091swsrnmuPXIP_o }}\end{array}$ \\
\hline El Afiche. Periódico Digital & http://elafiche.mx/ \\
\hline Noticias en Código & https://www.codigonoticias.com.mx \\
\hline
\end{tabular}

Fuente: Elaboración propia

Los resultados vertidos en la tabla 2 anterior, nos muestran resultados comparables entre los periódicos digitales y los que aparecen de manera digital e impresa; aunque es probable que no esté contemplado el total de portales de ciberperiodismo por la falta de antecedentes o presencia de páginas web aún no consolidadas.

Cabe destacar también que a esta lista debemos añadir el avance y existencia de radio y televisión on line, tan solo en Sinaloa existen más de 40 estaciones de radio que operan o se escuchen en este estado y no a si el número de televisoras representadas prácticamente por las compañias de televisión TELEVISA y AZTECA en sus modalidades regionales o locales.

A pesar de los anteriores avances en el periodismo cibernético en Sinaloa es necesario subsanar las graves carencias en el uso de las herramientas propias del entorno digital que señalan un problema serio: es indispensable determinar sus causas, que pueden provenir desde las estrecheces económicas hasta la falta de capacitación y conocimiento sobre las potencialidades de tales recursos, además de que las redacciones digitales mexicanas no cuentan con estructuras laborales y profesionales adecuadamente identificadas. Se advierten esfuerzos dispersos y sin objetivos adecuados. 
La viabilidad del modelo de negocio es, necesariamente, uno de los temas obligados, los diarios en linea nacionales y en Sinaloa aún no encuentran la vía para garantizar su sobrevivencia. Ahondar en la investigación de las características de los diarios digitales y sus mercados permitirá esbozar estrategias que ataquen esta problemática (Barrios, 2013).

Es interesante destacar respecto al futuro del ciberperiodismo lo que rescata Crovi (2016) del trabajo presentado por Miège (2006) el cual sugiere que las industrias culturales mediáticas, entre las cuales se encuentra la prensa, están experimentando mutaciones que llevan también a cambios en los contenidos que ofrecen.

Enumera seis tipos de mutaciones: 1) de orden financiero; 2) técnicas y socio-técnicas; 3) en la distribución y difusión de los productos culturales e informativos; 4) en las prácticas de consumo; 5) en los soportes de cultura e información, y 6) en las relaciones entre arte, cultura y comunicación.

Resulta interesante su propuesta, que compartimos, porque estos seis puntos señalan la complejidad del proceso que llamamos "ciberperiodismo", un proceso en el cual están presentes tanto aspectos técnicos y económicos, como culturales. De ahí la necesidad de realizar estudios longitudinales, que no señalen solo datos numéricos, sino que sean capaces de ver como hecho multidimensional la nueva producción informativa en línea. 


\section{Conclusiones}

El ciberpriodimo en México al igual que a nivel internacional tiene aún un largo camino por recorrer ya que son variados los factores que determinan su crecimiento y consolidación, ente ellos se cuentan los económicos, técnicos, culturales entre otros, por lo que los estudios e investigaciones actuales aun no contemplan un modelo multidimensional tal y como lo afirman los principales investigadores en esta rama, sobre todo en Iberoamérica. Muchos de los ciberperiodicos existentes se localizan aún en una primera o segunda generación en México, la tercera sería suplir la prensa escrita por la digital.

Según estudios realizados recientemente demuestran una tendencia interesante detectada en este análisis en la que varios de los cibermedios mejor valorados pertenecen a la zona noroeste de México, conformada por los estados de Sinaloa, Sonora y Baja California Norte, lo que indica una tendencia de competencia positiva en esa región, en la que se destacan los periódicos el Debate y el Noroeste en Sinaloa.

A pesar de los anteriores avances en el periodismo cibernético en Sinaloa es necesario subsanar las graves carencias en el uso de las herramientas propias del entorno digital que señalan un problema serio: es indispensable determinar sus causas, que pueden provenir desde las estrecheces económicas hasta la falta de capacitación y conocimiento sobre las potencialidades de tales recursos, además de que las redacciones digitales mexicanas no cuentan con estructuras laborales y profesionales adecuadamente identificadas. Se advierten esfuerzos dispersos y sin objetivos adecuados.

En Sinaloa a pesar de ser uno de los estados en donde se dieron los primeros avances en esta materia, junto con otros estados del noroeste de México, aún adolece de una consolidación; hay avances importantes 
en alguno medios de prensa digitales y los que que combinan sus actividades con la prensa tradicional o escrita. Al igual que a nivel nacional la información es dispersa y los estudios son escasos o nulos, lo cual dificulta la obtención de antecedentes y de realizar un análisis más completo sobre el mismo. 


\section{Referencias}

Armañanzas, E., Díaz, N. J. y Meso, A, K. (1996). El periodismo electrónico, información y servicios multimedia en la era del ciberespacio. Barcelona: Ariel.

Barrios, P. A. (2013) ciberperiodismo en México: realidades, desafios y oportunidades. Tesis Doctoral. Facultad de Ciencias de la Comunicación. Universidad de Santiago de Compostela, 433P.

Crovi, D., Toussaint, F; Tovar, A. (2005). Periodismo Digital en México. México, D.F.: Universidad Nacional Autónoma de México.

Crovi, D. D. (2016). CIberperiodismo en Iberoamérica Coord. Ramón Salaverrìa. Ed. Fundación Telefónica y Ariel, S. A. Capítulo 13. México. Pp.242-253.

Díaz, N. J y Meso A. K. (1999). Periodismo en internet, modelos de la prensa digital. Bilbao: Editorial Universidad del País Vasco

Espinosa, M.V.A. (2013) El Ciberperiodismo hispano en persepectiva perspectiva http://cuadrivio.net/dossier/el-ciberperiodismo-hispano-en-perspectiva/

Franco, G. (2008). Cómo escribir para la web. Austin, Texas: Centro Knight para el Periodismo en las Américas. Recuperado de http://knightcenter.utexas.edu/es/ebook/como-escribir-para-la-web-como-escreverpara-web

Franco, G. (2009). Necesidades de formación para medios digitales en América Latina. Fundación Nuevo Periodismo Iberoamericano. Recuperado de http://www.maestrosdelweb.com/images/2009/12/libro-mediosdigitaleslat.pdf

Franco, G. (2010). El impacto de las tecnologías digitales en el periodismo y la democracia en América Latina. Austin, Texas: Centro Knight para el Periodismo en las Américas de la Universidad de Texas / Open Society Foundations Media Program. Recuperado de http://knightcenter.utexas.edu/es/node/1012

Gil, Q. (1999)- "Diseñando el periodista digital", en Sala de Prensa, 13, año II, Vol. 2, recuperado el 16 de noviembre de 2009 de http://www.saladeprensa.org/art89.htm

INEGI (2012). Encuesta Nacional de Ingresos y Gastos de los Hogares, 2012

INEGI (2015). Encuesta Nacional de Ingresos y Gastos de los Hogares, 2015

Islas, O., et al. (2000). Internet: el medio inteligente. México, D.F: Cecsa. 
Islas, O., et al. (2002). Explorando el Ciberperiodismo Iberoamericano. México: CECSAGrupo Patria Cultural.

López A. J. L. (2010). La ciberdocumentación en la prensa digital de México: servicios y productos ciberdocumentales. Tesis doctoral inédita. Madrid: Universidad Complutense de Madrid. Recuperado de http://eprints.ucm.es/10091/

Miège, B. (2006). La concentración en las industrias culturales y mediáticas (ICM) y los cambios en los contenidos. Cuadernos de Información y Comunicación, 11, 155-166.

Menéndez, A. M. y Toussaint, F. (1989). Prensa y nueva tecnología. México: Trillas.

Meneses, M. E. (2010). La industria del periodismo y su transición a la convergencia digital: ciberperiódicos y periodistas convergentes en México. Revista Virtualis (2) 44-58. Disponible en http://www2.ccm.itesm.mx/ehcs/dec/archivos/virtualis2.pdf

Morales, (2005) "Tendencias y debates actuales en el periodismo digital», en Signo y Pensamiento, vol. XXIV, núm. 47, julio-diciembre de 2005, p. 92.

Navarro Z. L. (2002). Los periódicos online. San Luis Potosí, México: Universidad Autónoma de San Luis Potosí.

Navarro Z. L. (2005). Los medios mexicanos en línea. Revista Mexicana de Comunicación, (90) 32-35.

Navarro, Z. L. (2011). Correspondencias \& Análisis, Nº 1.

Navarro, Z. L. (2012). Elementos de Ciberperiodismo. México: Editorial Fundación Manuel Buendia.

Palacios, M. y Díaz N. J. (2007). Ciberperiodismo, métodos de investigación. Una aproximación multidisciplinar en perspectiva comparada. Bilbao: Servicio Editorial de la Universidad del País Vasco. Recuperado de http://www.ehu.es/argitalpenak/images/stories/libros_gratuitos_en_pdf/Ciencias_Soci ales/Ciberperiodismo\%20\%20Metodos $\% 20 \mathrm{de} \% 20$ investigacion.pdf

Piedras, E. y Camargo, R. (2014). "Disparidad digital en el día de Internet». The Competitive Intelligence Unit. Disponible en http://www.the-ciu.net

Rivera, D. (2009) "Evolución del ciberperiodismo en Ecuador a través de los periódicos de Loja», en Razón y Palabra, p. 15.

Salaverría, R. y Díaz, N. J. (2003). Manual de redacción ciberperiodística Priemra Edición. Ed, Ariel, Barcelona, 589p. 
Salaverría, R. (2005). Redacción periodística en Internet, p. 21.

Trejo, D. R. (1996). La Nueva Alfombra Mágica. Madrid: Fundesco. 